\title{
Prevalence and risk factors for renal artery stenosis and chronic kidney disease in Japanese patients with peripheral arterial disease
}

\author{
Michiko Endo ${ }^{1}$, Hisao Kumakura ${ }^{1}$, Hiroyoshi Kanai ${ }^{1}$, Yoshihiro Araki ${ }^{1}$, Shu Kasama ${ }^{1}$, Hiroyuki Sumino ${ }^{1}$, \\ Shuichi Ichikawa ${ }^{1}$ and Masahiko Kurabayashi ${ }^{2}$
}

The prevalence and risk factors for renal artery stenosis (RAS) and chronic kidney disease (CKD) are unclear in Japanese patients with peripheral arterial disease (PAD). To examine these issues, we performed renal angiography in 410 patients with PAD. Renal function and damage were assessed using the estimated glomerular filtration rate (eGFR) and urinary level of microalbumin (MA). Multiple logistic and multiple regression analyses were used to examine the relationships of potential risk factors with RAS and CKD. In all, 94 subjects $(22.9 \%)$ had RAS $>50 \%$ and 45 subjects $(11.0 \%)$ had RAS $>75 \%$. The incidences of an abnormal level of MA and renal insufficiency (eGFR $<60 \mathrm{ml} \mathrm{min}^{-1}$ per $1.73 \mathrm{~m}^{2}$ ) were 37.0 and $60.7 \%$, respectively. RAS $\geqslant 50 \%$ was associated with critical limb ischemia (CLI; hazard ratio (HR) 2.519; $95 \%$ confidence interval (CI) 1.203-5.276, $P=0.014$ ), coronary heart disease (CHD; HR 2.143; 95\% CI 1.129-4.069; $P=0.020$ ) and hypertension (HR 1.907; 95\% Cl 1.009-3.628; $P=0.045$ ). RAS $\geqslant 75 \%$ had a relationship with hypertension (HR $3.093 ; 95 \% \mathrm{Cl}$ 1.002-9.548; $P=0.048)$. eGFR was negatively correlated with age, uric acid and CHD $(P=0.013)$, and MA had a significant positive correlation with low-density lipoprotein cholesterol, CLI, age, CHD and diabetes $(P<0.001)$. These results show that the prevalences of RAS and CKD are very high in Japanese patients with PAD; that CLI and CHD are major risk factors for RAS; and that hyperuricemia, hypercholesterolemia and diabetes are risk factors for CKD in PAD. We also found that MA is a simple and noninvasive marker of renal dysfunction and general vascular damage.

Hypertension Research (2010) 33, 911-915; doi:10.1038/hr.2010.93; published online 10 June 2010

Keywords: chronic kidney disease; microalbuminuria; peripheral arterial disease; renal artery stenosis

\section{INTRODUCTION}

Atherosclerotic renal artery stenosis (RAS) is a cause of severe hypertension, pulmonary edema and renal dysfunction. ${ }^{1,2}$ Recent studies have shown a high prevalence of RAS in patients with peripheral arterial disease (PAD) or coronary heart disease (CHD). ${ }^{1,3}$ However, many cases of RAS do not present with specific symptoms or signs of ischemia, unlike PAD or CHD, and there is little information on the prevalence of RAS in Japanese patients with PAD. $\mathrm{PAD}$ is an atherosclerotic disease that has multiple atherosclerosis risk factors and a high incidence of coexisting atherosclerotic vascular disease. ${ }^{4} \mathrm{PAD}$ is also frequently associated with chronic kidney disease (CKD), ${ }^{5,6}$ which also seems to be a risk factor for CHD and cerebral vascular disease. ${ }^{5,7}$ However, the prevalence and degree of CKD and the associated risk factors in patients with $\mathrm{PAD}$ are also unclear.

Recent studies of the estimated glomerular filtration rate (eGFR) have shown that this parameter is a better predictor of mortality than serum creatinine alone in patients with PAD. ${ }^{5,6}$ Moreover, microalbuminuria is independently associated with increased cardiovascular risk factors and cardiovascular morbidity. ${ }^{8,9}$ Therefore, in this study, we investigated the prevalence of RAS and clinical factors related to RAS in Japanese patients with PAD independent of hemodialysis. We also examined various risk factors for CKD based on evaluation of eGFR or urinary microalbumin (MA) in patients with PAD.

\section{METHODS}

Patients

The subjects of the study were patients with PAD who were admitted to our hospital and received endovascular treatment between July 2004 and August 2008 because of iliac or femoral artery stenosis of $\geqslant 70 \%$ on angiography. Before the start of the study, the patients received a full explanation of the treatment and examination methods, and gave written informed consent. RAS was evaluated by digital subtraction angiography performed just before the start of endovascular treatment. The rate of stenosis was calculated bilaterally using automatic software from the manufacturer (Phillips Med, Best, The Netherlands) same as quantitative coronary angiography. Patients with a creatinine level of $\geqslant 2.5 \mathrm{mg}$ per $100 \mathrm{ml}$ and those with severe proteinuria such as that in nephrotic syndrome were excluded from the study, because these patients were

\footnotetext{
${ }^{1}$ Department of Internal Medicine, Cardiovascular Hospital of Central Japan (Kitakanto Cardiovascular Hospital), Shibukawa, Gunma, Japan and ${ }^{2}$ Department of Medicine and Clinical Science, Gunma University Graduate School of Medicine, Maebashi, Gunma, Japan

Correspondence: Dr H Kumakura, Department of Internal Medicine, Cardiovascular Hospital of Central Japan (Kitakanto Cardiovascular Hospital), Shimohakoda 740 Hokkitumachi Shibukawa, Gunma 377-0061, Japan.

E-mail: Kumakura@sannet.ne.jp

Received 11 March 2010; revised 8 April 2010; accepted 14 April 2010; published online 10 June 2010
} 
Table 1 Baseline clinical characteristics and risk factors in patients with PAD

\begin{tabular}{|c|c|c|c|c|}
\hline Risk factor & All patients, $\mathrm{n}=410$ & $R A S \geqslant 50 \%, \mathrm{n}=94(22.9 \%)$ & $\operatorname{RAS}(-), \mathrm{n}=316(77.1 \%)$ & P-value \\
\hline Age (year) & $71.0 \pm 9.1$ & $72.9 \pm 8.3$ & $70.5 \pm 9.2$ & 0.043 \\
\hline Gender (male) & $338(82.6 \%)$ & $81(86.2 \%)$ & $257(81.3 \%)$ & 0.394 \\
\hline $\mathrm{ABI}$ & $0.60 \pm 0.25$ & $0.53 \pm 0.24$ & $0.62 \pm 0.25$ & 0.007 \\
\hline BMI $\left(\mathrm{kg} \mathrm{m}^{-2}\right)$ & $22.1 \pm 3.7$ & $20.9 \pm 3.4$ & $22.4 \pm 3.3$ & 0.001 \\
\hline Hypertension & $247(60.2 \%)$ & $71(75.5 \%)$ & $176(55.6 \%)$ & 0.007 \\
\hline CHD & $122(29.8 \%)$ & $39(41.5 \%)$ & $83(26.3 \%)$ & 0.020 \\
\hline Cerebral infarction & $71(17.3 \%)$ & $26(27.7 \%)$ & $45(14.2 \%)$ & 0.009 \\
\hline Smoking & $317(77.3 \%)$ & $71(75.5 \%)$ & $246(77.8 \%)$ & 0.757 \\
\hline \multicolumn{5}{|l|}{ Laboratory data } \\
\hline Total-C (mg per $100 \mathrm{ml}$ ) & $192 \pm 40$ & $191 \pm 36$ & $192 \pm 40$ & 0.824 \\
\hline Lipoprotein (a) (mg per $100 \mathrm{ml}$ ) & $25.4 \pm 23.3$ & $27.4 \pm 25.5$ & $25.0 \pm 22.9$ & 0.447 \\
\hline RLP-C (mg per $100 \mathrm{ml})$ & $6.2 \pm 3.6$ & $5.8 \pm 3.3$ & $6.3 \pm 3.7$ & 0.286 \\
\hline Uric acid (mg per $100 \mathrm{ml})$ & $5.9 \pm 1.7$ & $5.6 \pm 1.7$ & $6.0 \pm 1.7$ & 0.126 \\
\hline Homocysteine $\left(\mathrm{nmol} \mathrm{ml^{-1 }}\right)$ & $13.8 \pm 8.7$ & $14.7 \pm 6.7$ & $13.6 \pm 9.1$ & 0.456 \\
\hline D-dimer ( $\mu \mathrm{g}$ per $100 \mathrm{ml}$ ) & $1.6 \pm 2.3$ & $1.7 \pm 1.8$ & $1.6 \pm 2.4$ & 0.785 \\
\hline Fibrinogen (mg per $100 \mathrm{ml}$ ) & $326 \pm 102$ & $357 \pm 102$ & $319 \pm 101$ & 0.009 \\
\hline U-MA (mg per g Cr) & $117 \pm 360$ & $141 \pm 353$ & $112 \pm 361$ & 0.621 \\
\hline
\end{tabular}

Abbreviations: $\mathrm{ABI}$, ankle brachial pressure index; $\mathrm{BMI}$, body mass index; $\mathrm{CHD}$, coronary heart disease; CLI, critical limb ischemia; DM, diabetes mellitus; eGFR, estimated glomerular filtration rate; $\mathrm{HbAlc}$, glycosylated hemoglobin Alc; HDL-C, high-density lipoprotein cholesterol; IC, intermittent claudication; LDL-C, low-density lipoprotein cholesterol; PAD, peripheral arterial disease; RAS, renal artery stenosis; RLP-C, remnant-like particle-cholesterol; Total-C, total cholesterol; U-MA, urinary microalbumin.

not eligible for endovascular treatment using an iodinated contrast material. Patients receiving hemodialysis were also excluded from the study.

\section{Risk factors}

Smoking history, hypertension, diabetes mellitus (DM), cerebral infarction and $\mathrm{CHD}$ were studied as risk factors for arteriosclerosis. Hypertension was defined as blood pressure of $\geqslant 140 / 90 \mathrm{~mm} \mathrm{Hg}$ recorded at least twice, or intake of antihypertensive agents. Diabetes was defined as a fasting plasma glucose level of $>126 \mathrm{mg}$ per $100 \mathrm{ml}$ for at least two measurements, or antidiabetic therapy. ${ }^{10}$ An electrocardiogram was recorded and echocardiography and a brain computed tomography scan were performed for each patient. Cerebral infarction was considered positive when the patient had a history of this condition or when lesions due to cerebral infarction were found in brain computed tomography. CHD was considered to be present when the patient had a history of this disease or showed a positive sign in stress/rest myocardial perfusion scintigraphy. Intermittent claudication and critical limb ischemia (CLI) were defined using the criteria of the Inter-Society Consensus for the Management of Peripheral Arterial Disease. ${ }^{4}$

Blood was collected during fasting in the morning for determination of total cholesterol, low-density lipoprotein (LDL) cholesterol, high-density lipoprotein cholesterol, triglyceride, lipoprotein (a), remnant-like particle-cholesterol, glycosylated hemoglobin Alc, homocysteine, glucose, uric acid, creatinine, D-dimer and fibrinogen. Freshly voided samples were collected for determination of urinary MA and creatinine. The degree of albuminuria was expressed as the $\mathrm{MA} /$ creatinine ratio ( $\mathrm{mg}$ per $\mathrm{gCr}$ ). Lipid abnormalities were diagnosed based on total cholesterol $\geqslant 220 \mathrm{mg}$ per $100 \mathrm{ml}$ or intake of lipid-lowering agents, ${ }^{11,12}$ high-density lipoprotein cholesterol $<40 \mathrm{mg}$ per $100 \mathrm{ml},{ }^{4,12}$ triglyceride $\geqslant 150 \mathrm{mg}$ per $100 \mathrm{ml},{ }^{12,13}$ and LDL cholesterol $\geqslant 140 \mathrm{mg}$ per $100 \mathrm{ml} \cdot{ }^{12}$

\section{Assessment of renal function}

The glomerular filtration rate was estimated using the MDRD (Modification of Diet in Renal Disease) equation for creatinine, as modified by the Japanese
Society of Nephrology: eGFR $\left(\mathrm{ml} \mathrm{min}^{-1}\right.$ per $\left.1.73 \mathrm{~m}^{2}\right)=194 \times(\mathrm{Scr})^{-1.094} \times$ $(\text { age })^{-0287}\left(\times 0.739\right.$ if female).$^{14}$ CKD was divided into five stages according to NKF-K/DOQl (The National Kidney Foundation-Kidney Disease Outcomes Quality Initiative) guidelines. ${ }^{15}$ Glomerular function was also assessed by measuring the urinary level of MA. Microalbuminuria was diagnosed based on $\mathrm{MA} \geqslant 30 \mathrm{mg}$ per $\mathrm{g} \mathrm{Cr}$.

\section{Statistical analysis}

Data are expressed as mean values \pm s.d. The groups of patients with and without RAS were compared using a $t$-test and proportions were compared using $\chi^{2}$ test with Yates' correction. Factors with $P<0.07$ in this paired analysis were used in multivariate logistic analysis to determine predictors of RAS (hypertension, CHD, cerebral infarction, CLI, ankle brachial pressure index, body mass index, fibrinogen, age and eGFR). Relationships between eGFR or MA and the following risk factors were studied using stepwise forward multiple regression analysis: smoking, CLI, hypertension, DM, cerebral infarction and CHD as categorical factors; and age, ankle brachial pressure index, LDL cholesterol, high-density lipoprotein cholesterol, triglyceride, lipoprotein (a), remnant-like particle-cholesterol, glycosylated hemoglobin Alc, homocysteine, uric acid, D-dimer and fibrinogen as continuous variables. SPSS v.16.0 (SPSS, Chicago, IL, USA) was used for all calculations. A $P$-value of $<0.05$ was considered to indicate a significant difference.

\section{RESULTS}

\section{Patient characteristics}

The subjects were 410 patients with PAD (338 males and 72 females) aged 38-97 years old (mean $71.0 \pm 9.1$ years old). The characteristics of the patients, including complications and risk factors, are shown in Table 1 . Patients with RAS $\geqslant 50 \%$ were significantly older, and had higher fibrinogen and a lower ankle brachial pressure index and body mass index compared with those without RAS. Hypertension, CHD and cerebral infarction were significantly more common in patients 


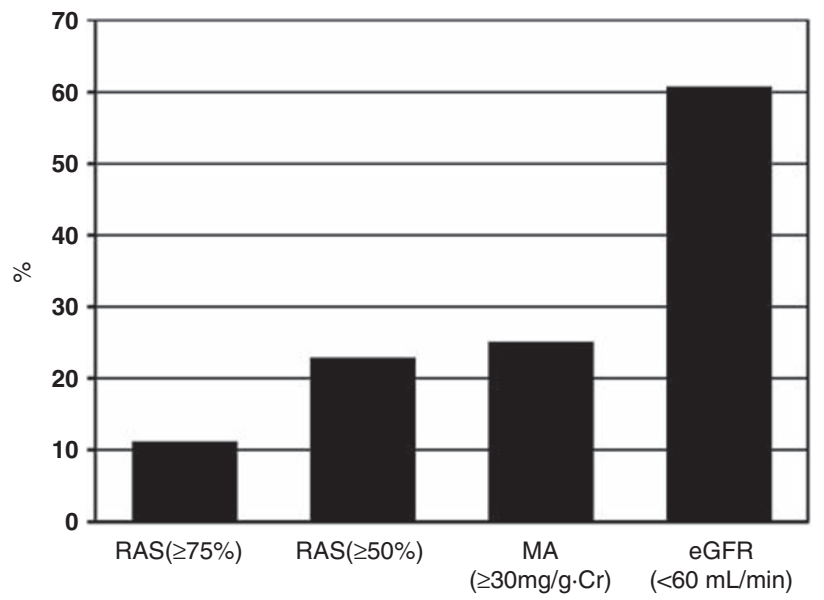

Figure 1 Prevalence of abnormal levels of renal artery stenosis (RAS), microalbumin (MA) and renal dysfunction (estimated glomerular filtration rate (eGFR) $<60 \mathrm{ml} \mathrm{min}^{-1}$ ).

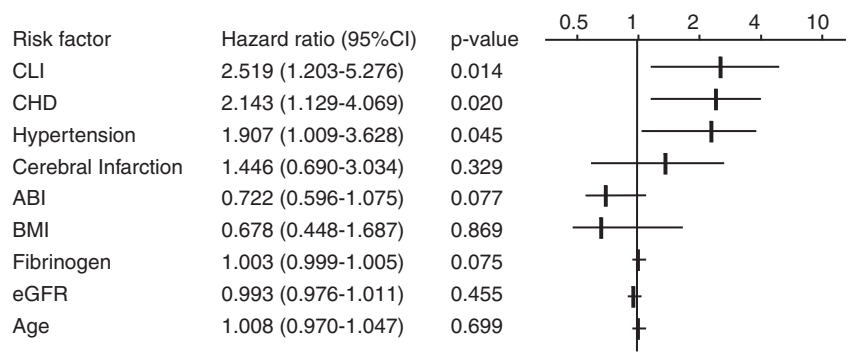

Figure 2 Relationship between renal artery stenosis and risk factors in multiple logistic analysis. $\mathrm{ABI}$, ankle brachial pressure index; $\mathrm{BMI}$, body mass index; CHD, coronary heart disease; CLI, critical limb ischemia; eGFR, estimated glomerular filtration rate.

with RAS. The prevalences of CLI and eGFR showed a tendency to differ between the two groups. There were no significant differences in other background data.

\section{Prevalence of RAS and renal dysfunction}

In all, 94 subjects $(22.9 \%)$ had RAS $\geqslant 50 \%$ and $45(11.0 \%)$ had RAS $\geqslant 75 \%$ (Figure 1). An abnormal level of MA was present in $25.1 \%$ (Figure 1). Only $4.2 \%$ of patients $(n=17)$ had normal kidney function $\left(\right.$ eGFR $\geqslant 90 \mathrm{ml} \mathrm{min}^{-1}$ per $\left.1.73 \mathrm{~m}^{2}\right), 35.1 \%(n=144)$ had mildly impaired kidney function (eGFR $60-89 \mathrm{ml} \mathrm{min}^{-1}$ per $1.73 \mathrm{~m}^{2}$ ), $58.5 \% \quad(n=240)$ had moderate renal insufficiency (eGFR 30 $59 \mathrm{ml} \mathrm{min}^{-1}$ per $\left.1.73 \mathrm{~m}^{2}\right), 2.0 \%(n=8)$ had severe renal insufficiency (eGFR $15-29 \mathrm{ml} \mathrm{min}^{-1}$ per $\left.1.73 \mathrm{~m}^{2}\right)$ and $0.2 \%(n=1)$ had renal failure (eGFR $<15 \mathrm{ml} \mathrm{min}^{-1}$ per $.73 \mathrm{~m}^{2}$ ). Thus, the prevalence of renal dysfunction (eGFR $<60 \mathrm{ml} \mathrm{min}^{-1}$ per $1.73 \mathrm{~m}^{2}$ ) was $60.7 \%$ (Figure 1 ).

\section{Risk factors for RAS and renal dysfunction}

Examination of the relationship between RAS $\geqslant 50 \%$ and potential risk factors using multiple logistic analysis revealed correlations with CLI, CHD and hypertension (Figure 2). The hazard ratio (HR) was 2.5 times higher in cases with CLI $(P<0.05)$ and 2.1 times higher in cases with CHD $(P<0.05)$. Multiple logistic analysis of RAS $\geqslant 75 \%$ and potential risk factors revealed a significant correlation with hypertension alone (HR 3.093; 95\% confidence interval (CI) 1.002-9.548; $P=0.048)$. Stepwise forward multiple regression analysis of the
Table 2 Correlations between eGFR and other risk factors in stepwise forward multiple regression analysis

\begin{tabular}{llccc}
\hline Risk factor & Units & $\beta$ & $95 \% \mathrm{Cl}$ & P-value \\
\hline Age & Year & -0.329 & -0.927 to -0.457 & 0.001 \\
Uric acid & mg per $100 \mathrm{ml}$ & -0.203 & -3.244 to -0.945 & 0.001 \\
CHD & & -0.142 & -9.823 to -1.177 & 0.013
\end{tabular}

Abbreviations: $\mathrm{CHD}$, coronary heart disease; $\mathrm{Cl}$, confidence interval; eGFR, estimated glomerular filtration rate.

$R^{2}=0.156, F$ for change in $R^{2}=6.277, P=0.013$.

Table 3 Correlations between urinary level of microalbumin and other risk factors in stepwise forward multiple regression analysis

\begin{tabular}{llccr}
\hline Risk factor & Units & $\beta$ & $95 \% \mathrm{Cl}$ & P-value \\
\hline LDL cholesterol & mg per $100 \mathrm{ml}$ & 0.255 & $1.224-3.579$ & $<0.001$ \\
CLI & & 0.186 & $70.18-344.98$ & 0.003 \\
Age & Year & 0.143 & $0.878-10.9434$ & 0.022 \\
CHD & & 0.137 & $11.263-206.44$ & 0.029 \\
DM & & 0.128 & $5.289-201.71$ & 0.039
\end{tabular}

Abbreviations: $\mathrm{CHD}$, coronary heart disease; $\mathrm{Cl}$, confidence interval; $\mathrm{CLI}$, critical limb ischemia; DM, diabetes mellitus; LDL, low-density lipoprotein

$R^{2}=0.127, F$ for change in $R^{2}=6.827, P<0.001$

relationship between eGFR and potential risk factors indicated that eGFR was negatively correlated with age, uric acid and CHD (Table 2, $P=0.013)$. MA was positively correlated with LDL cholesterol, CLI, age, CHD and DM (Table 3, $P<0.001$ ).

Peripheral endovascular treatment and RAS or renal dysfunction The initial success rate of endovascular treatment of PAD in all subjects was $95.4 \%(391 / 410)$. There was no significant correlation of this rate with RAS, eGFR or MA.

\section{DISCUSSION}

Our study of patients with PAD showed that $22.9 \%$ had RAS $>50 \%$ and $11.0 \%$ had RAS $>75 \%$. In a meta-analysis of patients with atherosclerotic risk factors such as hypertension, DM, CHD, CKD or $\mathrm{PAD}$, the prevalence of RAS has been reported to be $15.4 \% .{ }^{16}$ In multiple series of PAD cases, the rates of RAS varied from 12.0 to $45.5 \%$, with a pooled prevalence of $25.3 \% .{ }^{16}$ Wilms et al. ${ }^{17}$ found a $22 \%$ prevalence of RAS $\geqslant 50 \%$ in patients with PAD (mean age 62.4 years old), and Amighi et al. ${ }^{1}$ recently reported a prevalence of RAS $\geqslant 60 \%$ on angiography of $15.6 \%$ in patients with PAD (mean age 70.6 years old). Thus, our results for the rate of RAS in Japanese patients with PAD are similar to those found in previous studies.

Yamashita et al. ${ }^{18}$ reported that RAS also occurs frequently in Japanese patients with CHD and that the prevalence of RAS is higher in patients with established CHD: 10, 9 and 19\% in patients with 1-, 2- and 3-vessel disease, respectively. Our results suggest that the prevalence of RAS in patients with PAD is higher than that in patients with established CHD. Moreover, we found that hypertension, CLI and CHD were closely associated with RAS in patients with PAD. As the severity or number of atherosclerotic risk factors increased, the prevalence of RAS also increased. However, many cases of RAS do not present with specific symptoms of ischemia, unlike CHD or PAD, and incidental RAS has been reported to be an independent predictor of mortality in patients with PAD. ${ }^{19}$ Therefore, screening for RAS is very important for management of patients with PAD. 
RAS reflects a high overall atherosclerotic burden that manifests as coronary, cerebrovascular and peripheral vascular disease. ${ }^{2}$ The goals of therapy for RAS center on effective reduction of blood pressure and stabilization of renal function. Revascularization with angioplasty or a stent is a direct hemodynamic treatment, ${ }^{20}$ but a recent comparison of randomized revascularization with medical therapy for RAS found no significant difference in the clinical benefit. ${ }^{21}$ Further studies are needed to confirm the optimal treatment for improving mortality and stabilization of renal function in patients with RAS.

Several studies have suggested that CKD is a prognostic indicator of $\mathrm{CVD},{ }^{5,22,23}$ and an association between survival and eGFR or estimated creatinine clearance in patients with PAD has recently been proposed. ${ }^{6,24,25}$ O'Hare et al. ${ }^{24}$ found that CKD was a strong independent predictor of mortality in patients with CLI and that the mortality risk was highest among patients with eGFR $<30 \mathrm{ml} \mathrm{min}^{-1}$ per $1.73 \mathrm{~m}^{2}$. It has also been shown that eGFR is an independent predictor of death and limb loss after infrainguinal bypass. ${ }^{25}$

Hyperuricemia has been reported to be a risk factor for development of CKD, and elevated levels of uric acid independently increase the risk for onset of new CKD in the general population and in patients with $\mathrm{DM}^{26,27}$ In this study, eGFR was negatively correlated with age, uric acid and CHD. The mechanisms underlying hyperuricemia as a result of reduced renal clearance of uric acid may involve a reduced GFR or dysfunctional handling of filtered uric acid by proximal tubules. ${ }^{28}$ In a community-based study of Japanese adults, hyperuricemia and age emerged as significant risk factors for renal failure, and hyperuricemia was more strongly predictive than proteinuria. ${ }^{29}$ Our study also highlights the correlation between CKD and the level of uric acid. As CKD seems to be a risk factor in PAD, ${ }^{4}$ treatment for hyperuricemia is important in patients with PAD.

Glomerular function was also assessed by measuring the urinary level of MA. Urinary MA excretion because of DM has been proposed to be a sign of atherosclerotic involvement of systemic arterial disease, in addition to $\mathrm{CKD}^{7,8}$ Furthermore, any degree of albuminuria is a risk factor for cardiovascular events in individuals with or without DM. ${ }^{30,31}$ Increased urinary MA excretion reflects generalized endothelial dysfunction and more widespread vascular damage. ${ }^{32,33}$ In this study, multiple regression analysis revealed a significant positive correlation of MA with LDL cholesterol, CLI, age, CHD and DM. This suggests that systemic atherosclerosis, as represented by CLI, $\mathrm{CHD}$ and higher LDL cholesterol, is also a cause of hypermicroalbuminuria in patients with PAD. MA is thought to reflect both renal damage and general vascular damage. The association of MA with systemic atherosclerosis is of interest, as noninvasive determination of the subgroup of patients with a high risk of coexistent diseases caused by atherosclerosis is difficult. Many patients with CKD have few clinical symptoms, which explains why the disease awareness of $\mathrm{CKD}$ is low despite the high prevalence rates, and increased MA excretion may also be a marker of CHD in patients with PAD. ${ }^{34}$ Thus, measurement of the excretion rate of MA using a simple and noninvasive procedure may be useful in non-diabetic patients with PAD, in addition to measurement of eGFR.

The initial success rate of endovascular treatment of PAD was not significantly correlated with RAS, eGFR or MA. However, we have reported that the in-stent neointimal proliferation rate shows a significant positive correlation with the serum creatinine level at 6 months after endovascular treatment. ${ }^{35}$ We have also reported a 10 year patency after endovascular treatment of the iliac artery. ${ }^{36}$ The restenosis rate showed no significant correlation with the serum creatinine level, and only stent use and the postprocedural stenosis rate were significant restenosis factors for long-term patency.

\section{Study limitations}

The limitations of our study are as follows. First, the subjects were limited to patients with PAD who received endovascular treatment because of iliac or femoral artery stenosis of $\geqslant 70 \%$ on angiography. Second, patients with a creatinine concentration of $\geqslant 2.5 \mathrm{mg}$ per $100 \mathrm{ml}$ or nephrotic syndrome and those receiving hemodialysis were excluded from the study. Therefore, evaluation of RAS in this group was not achieved, because these patients with CKD are not suited to endovascular treatment and most patients under hemodialysis have occluded trunks or distal branches of the renal artery. Third, the sample sizes were relatively small, the study was performed at a single facility and we did not use population-based data. Therefore, further studies are needed to reveal the precise prevalence and risk factors for RAS in patients with PAD.

\section{CONCLUSION}

Patients with PAD had high rates of complication with RAS and CKD. CLI, CHD and hypertension were found to be major risk factors for RAS; eGFR showed negative correlations with age, uric acid and CHD; and MA was positively correlated with LDL cholesterol, CLI, age, CHD and DM in our PAD population, which had the limitations noted above. These results indicate that complication with CHD is an important and comprehensive risk factor for RAS and CKD in patients with PAD.

1 Amighi J, Schlager O, Haumer M, Dick P, Mlekusch W, Loewe C, Bohmig G, Koppensteiner R, Minar E, Schillinger M. Renal artery stenosis predicts adverse cardiovascular and renal outcome in patients with peripheral artery disease. Eur $J$ Clin Invest 2009; 39: 784-792.

2 Garovic VD, Textor SC. Renovascular hypertension and ischemic nephropathy. Circulation 2005; 112: 1362-1374.

3 Ghaffari S, Sohrabi B, Siahdasht RB, Pourafkari L. Prevalence and predictors of renal artery stenosis in hypertensive patients undergoing coronary angiography. Hypertens Res 2009; 32: 1009-1014.

4 Norgren L, Hiatt WR, Dormandy JA, Nehler MR, Harris KA, Fowkes FG. Inter-Society Consensus for the Management of Peripheral Arterial Disease (TASC II). J Vasc Surg 2007; 45 (Suppl S): S5-S67.

5 Sarnak MJ, Levey AS, Schoolwerth AC, Coresh J, Culleton B, Hamm LL, McCullough PA, Kasiske BL, Kelepouris E, Klag MJ, Parfrey P, Pfeffer M, Raij L, Spinosa DJ, Wilson PW. Kidney disease as a risk factor for development of cardiovascular disease: a statement from the American Heart Association Councils on Kidney in Cardiovascular Disease, High Blood Pressure Research, Clinical Cardiology, and Epidemiology and Prevention. Circulation 2003; 108: 2154-2169.

6 Maithel SK, Pomposelli FB, Williams M, Sheahan MG, Scovell SD, Campbell DR, LoGerfo FW, Hamdan AD. Creatinine clearance but not serum creatinine alone predicts long-term postoperative survival after lower extremity revascularization. Am J Nephrol 2006; 26: 612-620

7 Nakamura M, Yamashita T, Yajima J, Oikawa Y, Ogasawara K, Kirigaya H, Sagara K, Koike A, Sawada H, Aizawa T. Impact of reduced renal function on prognosis in Japanese patients with coronary artery disease: a prospective cohort of Shinken Database 2007. Hypertens Res 2009; 32: 920-926.

8 Hillege HL, Janssen WM, Bak AA, Diercks GF, Grobbee DE, Crijns HJ, Van Gilst WH, De Zeeuw D, De Jong PE. Microalbuminuria is common, also in a nondiabetic, nonhypertensive population, and an independent indicator of cardiovascular risk factors and cardiovascular morbidity. J Intern Med 2001; 249: 519-526.

9 Jager A, Kostense PJ, Ruhe HG, Heine RJ, Nijpels G, Dekker JM, Bouter LM, Stehouwer $\mathrm{CD}$. Microalbuminuria and peripheral arterial disease are independent predictors of cardiovascular and all-cause mortality, especially among hypertensive subjects: fiveyear follow-up of the Hoorn Study. Arterioscler Thromb Vasc Biol 1999; 19: 617-624.

10 Expert Committee on the Diagnosis and Classification of Diabetes Mellitus. Report of the expert committee on the diagnosis and classification of diabetes mellitus. Diabetes Care 2003; 26(Suppl 1): S5-S20.

11 Okamura T, Tanaka H, Miyamatsu N, Hayakawa T, Kadowaki T, Kita Y, Nakamura Y, Okayama A, Ueshima $\mathrm{H}$. The relationship between serum total cholesterol and all-cause or cause-specific mortality in a 17.3-year study of a Japanese cohort. Atherosclerosis 2007; 190: 216-223.

12 Teramoto T, Sasaki J, Ueshima H, Egusa G, Kinoshita M, Shimamoto K, Daida H, Biro S, Hirobe K, Funahashi T, Yokote K, Yokode M. Executive summary of Japan Atherosclerosis Society (JAS) guideline for diagnosis and prevention of atherosclerotic cardiovascular diseases for Japanese. J Atheroscler Thromb 2007; 14: 45-50. 
13 Castelli WP. Lipids, risk factors and ischaemic heart disease. Atherosclerosis 1996; 124(Suppl): S1-S9.

14 Matsuo S, Imai E, Horio M, Yasuda Y, Tomita K, Nitta K, Yamagata K, Tomino Y, Yokoyama $\mathrm{H}$, Hishida A. Revised equations for estimated GFR from serum creatinine in Japan. Am J Kidney Dis 2009; 53: 982-992.

15 National Kidney Foundation. K/DOQI clinical practice guidelines for chronic kidney disease: evaluation, classification, and stratification. Am J Kidney Dis 2002; 39: S1-S266.

16 de Mast $\mathrm{Q}$, Beutler JJ. The prevalence of atherosclerotic renal artery stenosis in risk groups: a systematic literature review. J Hypertens 2009; 27: 1333-1340.

17 Wilms G, Marchal G, Peene P, Baert AL. The angiographic incidence of renal artery stenosis in the arteriosclerotic population. Eur J Radiol 1990; 10: 195-197.

18 Yamashita T, Ito F, Iwakiri N, Mitsuyama H, Fujii S, Kitabatake A. Prevalence and predictors of renal artery stenosis in patients undergoing cardiac catheterization. Hypertens Res 2002; 25: 553-557.

19 Mui KW, Sleeswijk M, van den Hout H, van Baal J, Navis G, Woittiez AJ. Incidental renal artery stenosis is an independent predictor of mortality in patients with peripheral vascular disease. J Am Soc Nephrol 2006; 17: 2069-2074.

20 White CJ. Catheter-based therapy for atherosclerotic renal artery stenosis. Circulation 2006; 113: 1464-1473.

21 The ASTRAL Investigators. Wheatley K, Ives N, Gray R, Kalra PA, Moss JG, Baigent C, Carr S, Chalmers N, Eadington D, Hamilton G, Lipkin G, Nicholson A, Scoble J. Revascularization versus medical therapy for renal-artery stenosis. N Engl J Med 2009, 361: 1953-1962.

22 Walsh CR, O’Donnell CJ, Camargo Jr CA, Giugliano RP, Lloyd-Jones DM. Elevated serum creatinine is associated with 1 -year mortality after acute myocardial infarction. Am Heart J 2002; 144: 1003-1011.

23 Kagiyama S, Matsumura K, Ansai T, Soh I, Takata Y, Awano S, Sonoki K, Yoshida A, Takehara T, lida M. Chronic kidney disease increases cardiovascular mortality in 80-year-old subjects in Japan. Hypertens Res 2008; 31: 2053-2058.

24 O'Hare AM, Bertenthal D, Shlipak MG, Sen S, Chren MM. Impact of renal insufficiency on mortality in advanced lower extremity peripheral arterial disease. J Am Soc Nephrol 2005; 16: 514-519.

25 Arvela E, Soderstrom M, Alback A, Aho PS, Tikkanen I, Lepantalo M. Estimated glomerular filtration rate (eGFR) as a predictor of outcome after infrainguinal bypass in patients with critical limb ischemia. Eur J Vasc Endovasc Surg 2008; 36: 77-83.
26 Weiner DE, Tighiouart H, Elsayed EF, Griffith JL, Salem DN, Levey AS. Uric acid and incident kidney disease in the community. J Am Soc Nephrol 2008; 19: 1204-1211.

27 Chen N, Wang W, Huang Y, Shen P, Pei D, Yu H, Shi H, Zhang Q, Xu J, Lv Y, Fan Q. Community-based study on CKD subjects and the associated risk factors. Nephrol Dial Transplant 2009; 24: 2117-2123.

28 Perez-Ruiz F, Calabozo M, Erauskin GG, Ruibal A, Herrero-Beites AM. Renal underexcretion of uric acid is present in patients with apparent high urinary uric acid output. Arthritis Rheum 2002; 47: 610-613.

29 Iseki K, Oshiro S, Tozawa M, Iseki C, Ikemiya Y, Takishita S. Significance of hyperuricemia on the early detection of renal failure in a cohort of screened subjects. Hypertens Res 2001; 24: 691-697.

30 Gerstein HC, Mann JF, Yi Q, Zinman B, Dinneen SF, Hoogwerf B, Halle JP, Young J, Rashkow A, Joyce $\mathrm{C}$, Nawaz $\mathrm{S}$, Yusuf $\mathrm{S}$. Albuminuria and risk of cardiovascular events, death, and heart failure in diabetic and nondiabetic individuals. JAMA 2001; 286: 421-426.

31 Hoshide S, Matsui Y, Shibasaki S, Eguchi K, Ishikawa J, Ishikawa S, Kabutoya T, Schwartz JE, Pickering TG, Shimada K, Kario K. Orthostatic hypertension detected by self-measured home blood pressure monitoring: a new cardiovascular risk factor for elderly hypertensives. Hypertens Res 2008; 31: 1509-1516.

32 Stehouwer CD, Nauta JJ, Zeldenrust GC, Hackeng WH, Donker AJ, den Ottolander GJ. Urinary albumin excretion, cardiovascular disease, and endothelial dysfunction in noninsulin-dependent diabetes mellitus. Lancet 1992; 340: 319-323.

33 Clausen P, Jensen JS, Jensen G, Borch-Johnsen K, Feldt-Rasmussen B. Elevated urinary albumin excretion is associated with impaired arterial dilatory capacity in clinically healthy subjects. Circulation 2001; 103: 1869-1874.

34 Sonmez K, Eskisar AO, Demir D, Yazicioglu MV, Mutlu B, Dogan Y, Izgi A, Mansuroglu $\mathrm{D}$, Bakal RB, Elonu $\mathrm{OH}$, Turan F. Increased urinary albumin excretion rates can be a marker of coexisting coronary artery disease in patients with peripheral arterial disease. Angiology 2006; 57: 15-20.

35 Kumakura H, Kanai H, Araki Y, Koizumi A, Kasama S, Sumino H, Ichikawa S. Effects of antiplatelet agents and other factors on neointimal proliferation in iliac artery stenting: Intravascular ultrasound analysis. Ann Vasc Dis 2009; 2: 100-108.

36 Koizumi A, Kumakura $H$, Kanai $H$, Araki $Y$, Kasama S, Sumino H, Ichikawa S, Kurabayashi M. Ten-year patency and factors causing restenosis after endovascular treatment of iliac artery lesions. Circ J 2009; 73: 860-866. 